\title{
Carcinoid tumour of the thymus gland: report of a case
}

\author{
J. PRESTON HUGHES ${ }^{1}$, NELSON A NCAL M O ${ }^{1}$, \\ GEORGEL. LEONARD ${ }^{2}$, and JOHN L. OCHSNER \\ Departments of Surgery ${ }^{1}$ and Pathology $y^{2}$, Alton Ochsner Medical Foundation, \\ New Orleans, Louisiana, USA
}

\begin{abstract}
Preston Hughes, J., Ancalmo, N., Leonard, G. L., and Ochsner, J. L. (1975). Thorax, 30, 470-475. Carcinoid tumour of the thymus gland: report of a case. Carcinoid of the thymus is a rare problem. A case is reported to add to only 16 previously reported. None of these 17 patients had the carcinoid syndrome. Complete surgical excision, if possible, is the treatment of choice.
\end{abstract}

A primary carcinoid tumour of the thymus is very rare. Rosai and Higa (1972) collected eight cases and found only eight additional cases in the literature. A patient with this unusual lesion was treated at Ochsner Foundation Hospital and the case report is presented, emphasizing the importance of complete excision.

\section{CASE REPORT}

A 32-year-old white man visited the emergency room on 16 February 1974, because of severe upper back and chest pain. The constant aching pain radiated anteriorly and down both arms; it was relieved by moving the shoulders but not by analgesics. He had had variable, recurrent chest and back pain for one year but no history of sweats, flushing, or diarrhoea.

The physical examination revealed no abnormality. Chest radiographs illustrated a large anterior mediastinal chest mass that protruded into the left side of the chest (Figs. 1 and 2).

Laboratory studies were within normal limits except for mild elevated blood sugar. After intravenous injection of $5 \mathrm{mCi} 99^{\mathrm{m}}$ technetium pertechnetate, an image of the thyroid gland was obtained using a stationary imaging device. The thyroid was normal with no substernal or mediastinal extensions. An arch aortogram illustrated no compression from the lesion and no vascular abnormalities. Some of the blood supply to the tumour originated from small left internal mammary artery branches. Pulmonary function studies were normal.

On 21 February the patient was operated on and a large anterior mediastinal tumour was re-sected through a median sternotomy. The involved pericardium and left phrenic nerve were excised. with the large discrete mass. Grossly, the tumouro measured $12 \times 9 \times 7 \mathrm{~cm}$ and weighed $290 \mathrm{~g}$ (Fig. 3 ). It was well-circumscribed, oval, and apparentlyo encapsulated; the cut surface was homogeneous, $\stackrel{\circ}{\varnothing}$ smooth, firm, grey-white, and fleshy. Micro- $\stackrel{\mathbb{Q}}{2}$ scopically the tumour was composed of small, $\overrightarrow{\vec{O}}$ closely packed cells with nuclei that were uniform 3 in size and shape with few mitotic figures (Figs? 4-6). The cytoplasm of the cells was diffusely? eosinophilic in most areas and vacuolated in others. No specific granules could be visualized.으 The ferric ferricyanide reduction technique to $x$ demonstrate argentaffin granules was negative. $\frac{0}{3}$ The cells were arranged in solid nests and trabeculae, with areas of tubular or acinar forma- -0 tion and other areas with the anastomosing ribbon- $₹$ like growth pattern characteristic of carcinoid 을 tumours. Abundant normal appearing thymic $>$ tissue was found in the adipose tissue surrounding을 an incomplete, irregular, fibrous tissue capsule.

Postoperatively paradoxical movement of the diaphragm was not a problem. Four days post- $\tilde{N}$ operatively $400 \mathrm{ml}$ of bloody pleural fluid was removed by thoracentesis. The patient was discharged one week postoperatively.

He was last seen on 22 July 1974 , with no complaints. The chest radiograph was normal.

\section{DISCUSSION}

The term carcinoid tumour was introduced by $\frac{7}{\mathbb{1}}$ Oberndorfer (1907) to designate a tumour which 


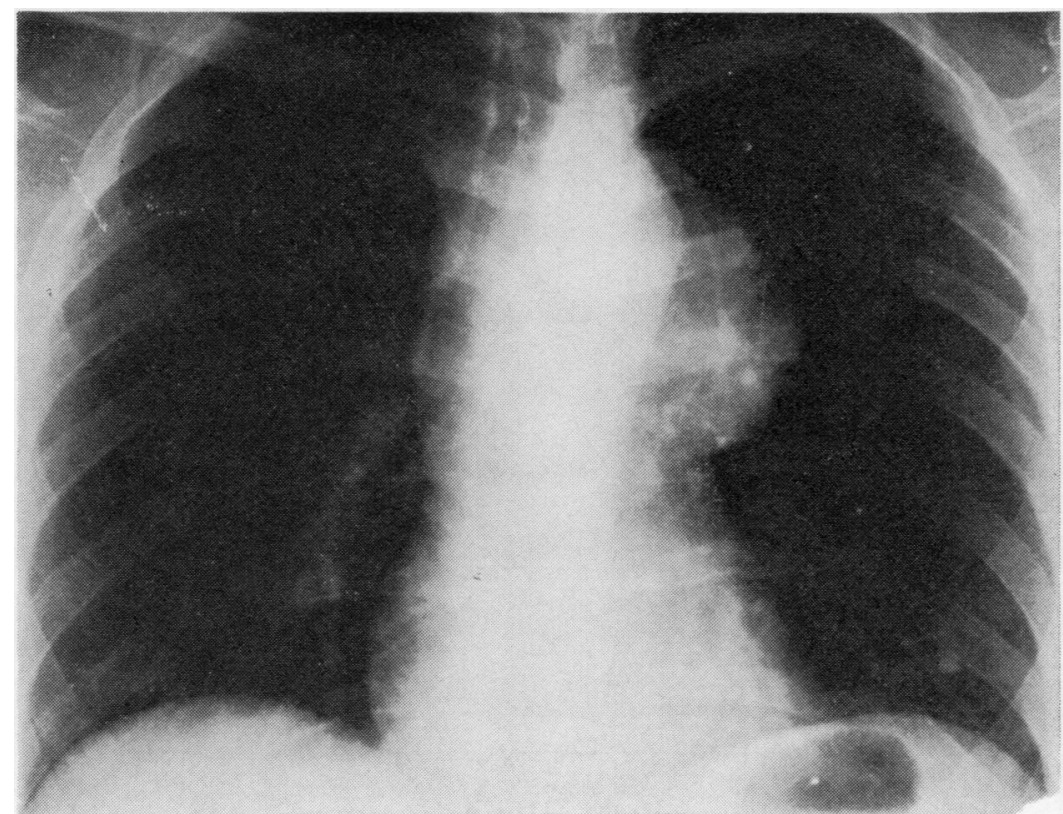

FIG. 1. Posteroanterior chest film illustrating the large size of the mediastinal tumour above the aortic arch.

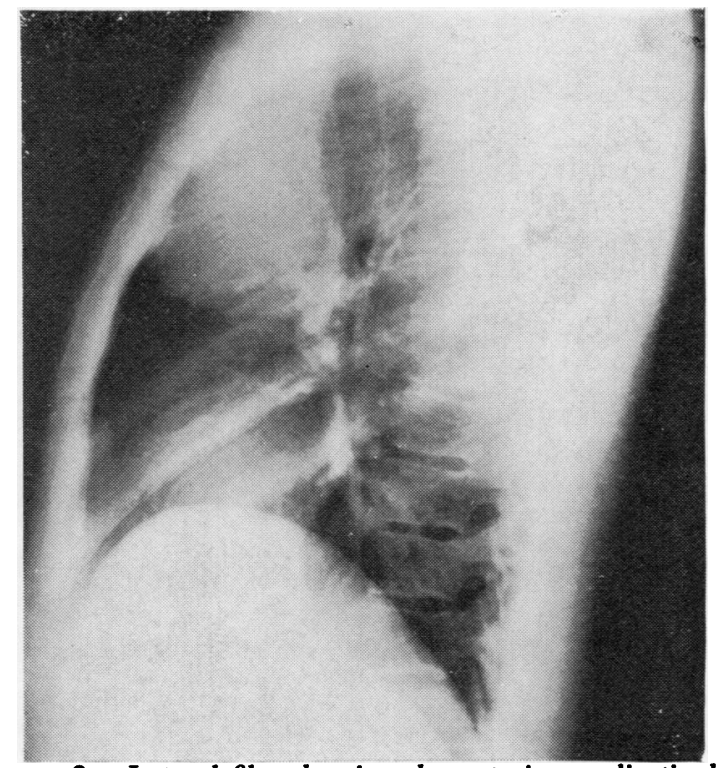

FIG. 2. Lateral film showing the anterior mediastinal location of the carcinoid tumour of the thymus gland. 


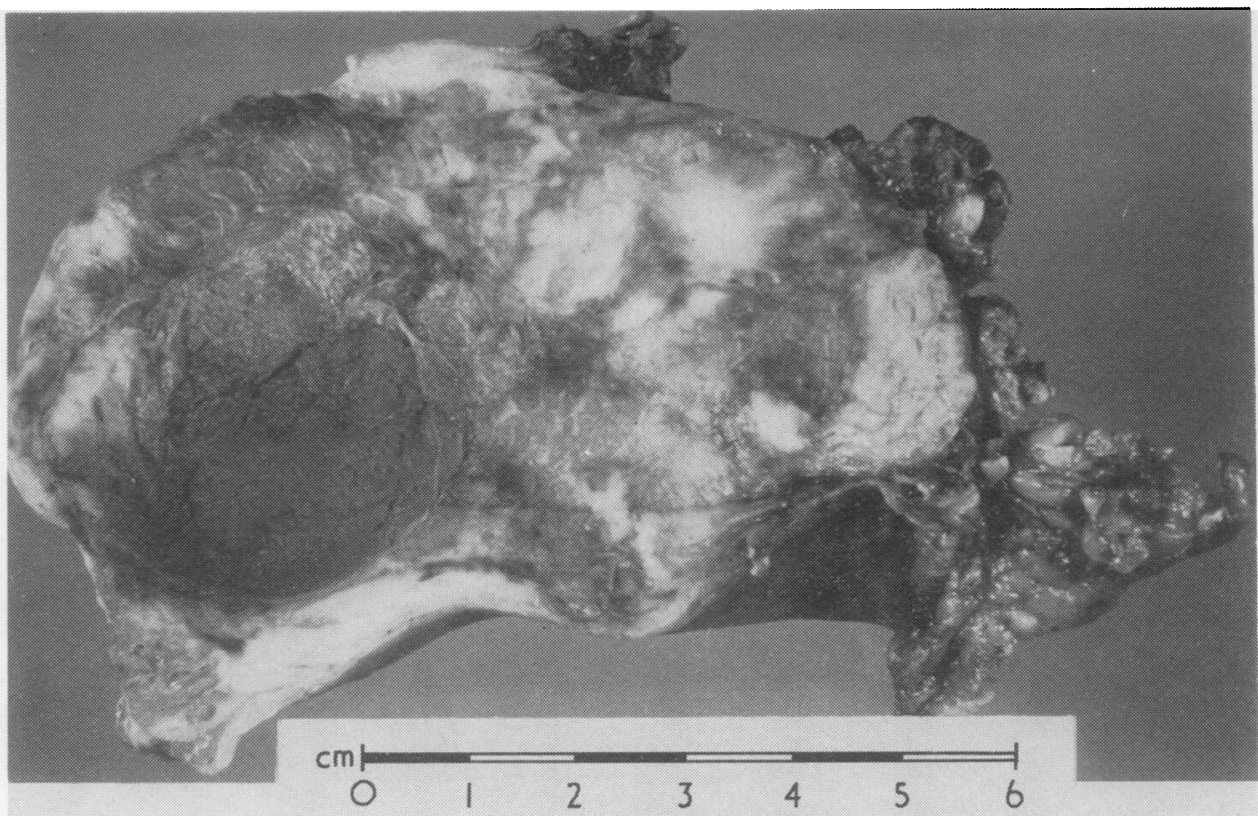

FIG. 3. Gross appearance of the tumour. Firm, grey-white areas alternate with areas of red-brown discoloration and one region of central necrosis.

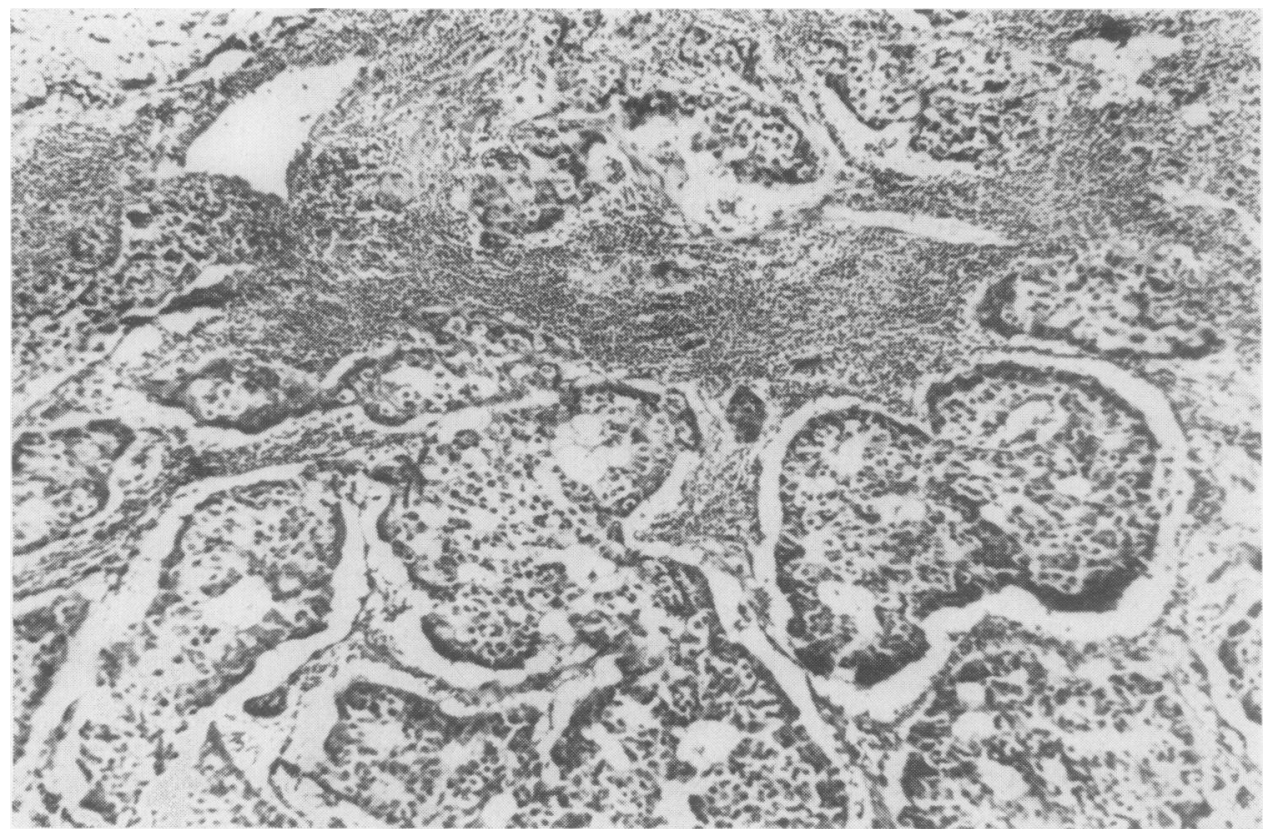

FIG. 4. Large alveolar nests of tumour, with areas of tubular or acinar formation, incompletely separated by inflamed fibrous stroma (Haematoxylin and Eosin $\times 77$ ). 


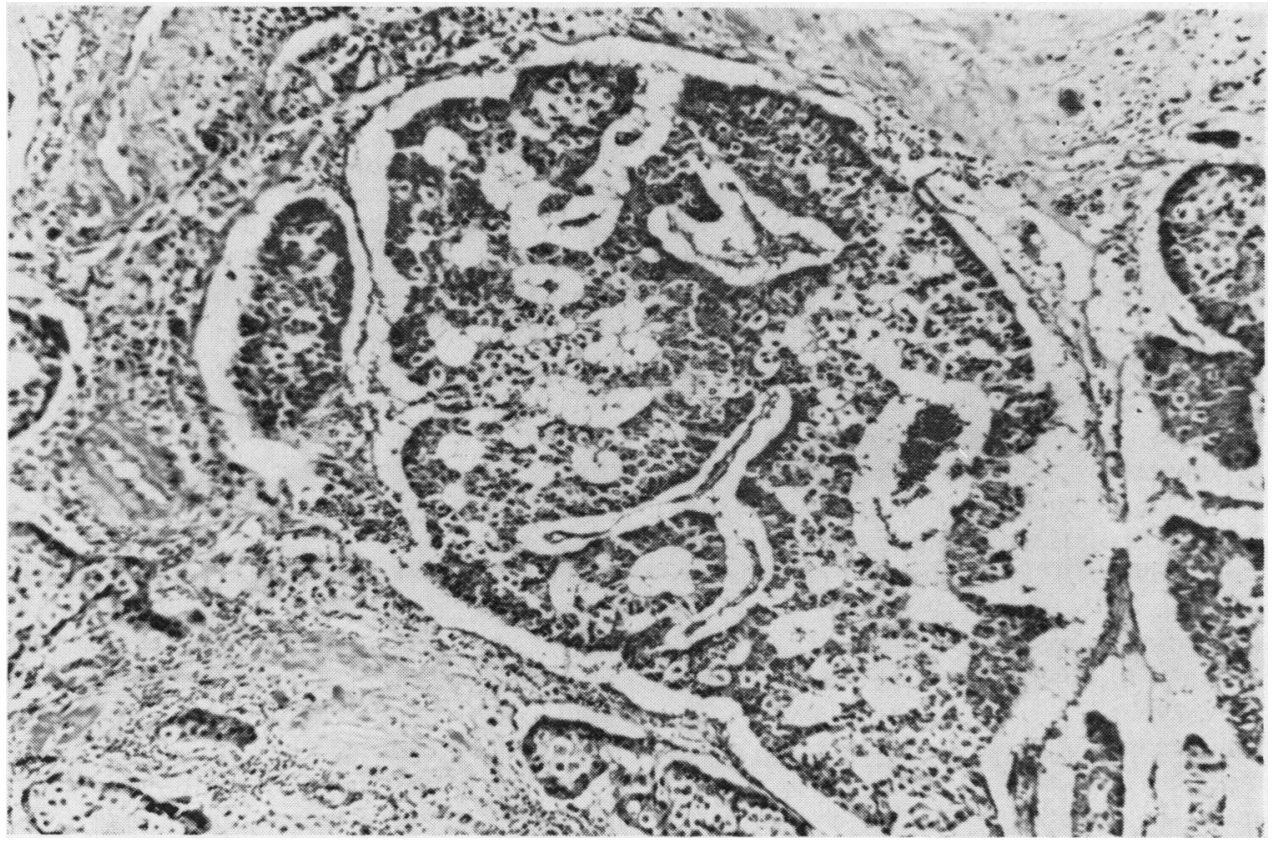

FIG. 5. Medullary pattern of radially arranged cells forming anastomosing columns and pseudoacinar formation. ( $H$ and $E \times 212$ ).

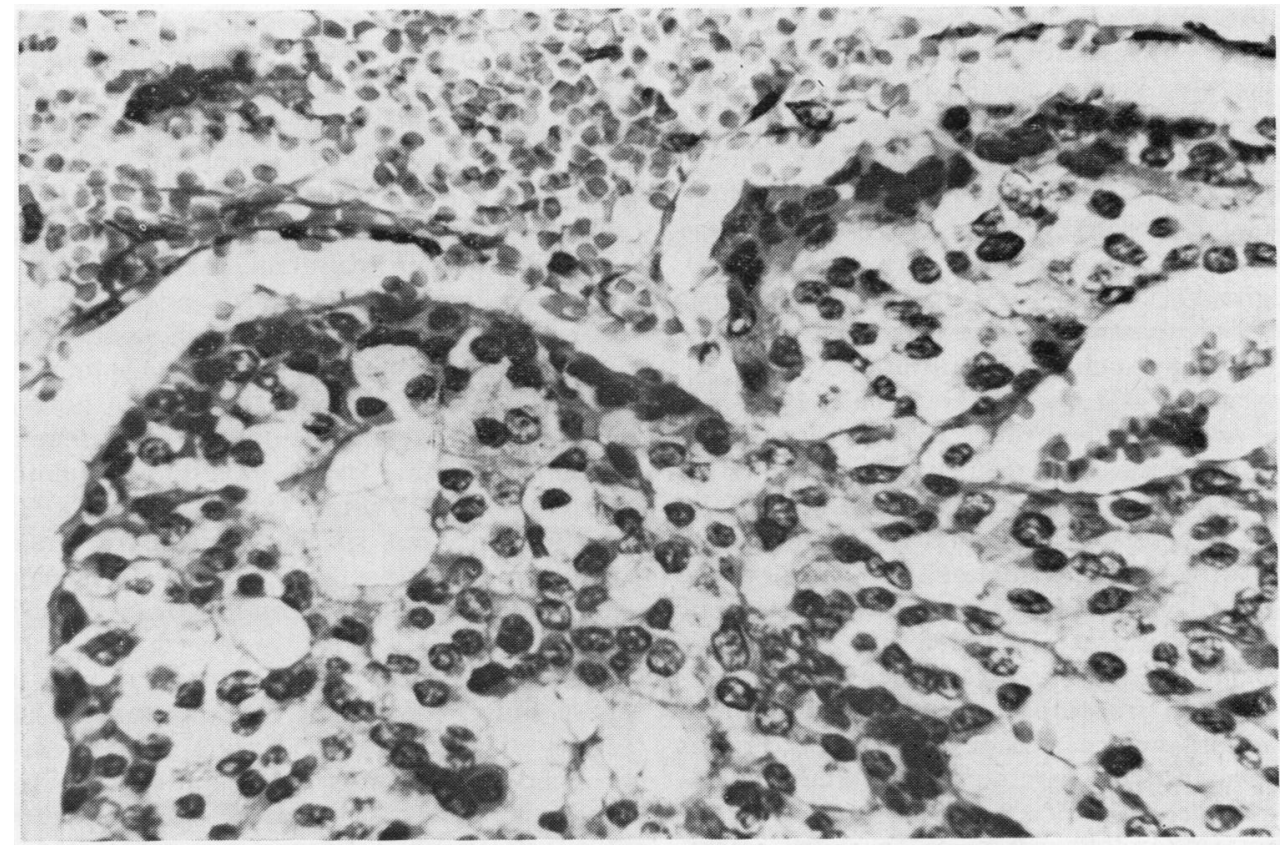

FIG. 6. Tumour cells having uniform nuclei with abundant eosinophilic or vacuolated cytoplasm (H and $E \times 377)$. 
resembled an undifferentiated carcinoma histologically but behaved in a benign fashion. When Pearson and Fitzgerald (1949) reported a series of metastasizing carcinoid tumours, the malignant potential was recognized.

Carcinoid tumours arise from argentaffin cells, originally described by Kultschitzky (1897) and often termed Kultschitsky cells. These cells, according to Bensch et al. (1968), 'are present in all structures derived from the primitive entodermal canal and include the derivatives of the pharyngeal arches, the tracheobronchial tree, the gastrointestinal canal, the pancreatic duct and the bile ducts'. Argentaffin granules also have been demonstrated in the thymus of some animals, and normal human thymus has some argyrophilic cells (Rosai and Higa, 1972). Kultschitsky cells are neuroendocrine cells shown by electron microscopy to contain neurosecretory granules reported to resemble alpha cells of the pancreas (Macadam and Vetters, 1969).

The tumours which arise from these cells, called argentaffinomas or carcinoid tumours, are found infrequently. In MacDonald's (1956) study carcinoids were found at necropsy in $102(0.4 \%)$ of 26401 subjects examined and were found in 254 $(0.06 \%)$ of 418166 surgical specimens. The most common site of the lesion is in the intestinal tract, especially the appendix and terminal ileum, and also in the rectum, colon, stomach, duodenum, and Meckel's diverticulum (Postlethwait, 1966). They have also been reported in the gallbladder (Shiffman and Juler, 1964), ovaries (Gabrilove, Nicolis, and Kirschner, 1969), lungs (Steel, Baerg, and Adams, 1967), pancreas (Peart et al., 1963), parotid gland (Rosai and Higa, 1972), testis (Rosai and Higa, 1972), bronchus (Gabrilove et al., 1969), thymus gland (Gabrilove et al., 1969), and in areas where ectopic gastric or intestinal epithelium is known to occur, such as in teratomas.

Many carcinoid tumours are small, less than $2 \mathrm{~cm}$ in greatest dimension. Typically, they are well-circumscribed, homogeneous, and yellow to grey-white in appearance. Microscopically the tumour is composed of epithelial cells, which have small uniform nuclei, associated with acidophilic or vacuolated cytoplasm. The growth pattern of the tumour cells is characteristic with cells arranged in alveolar nests, trabeculae, tubules, acini, and in an anastomosing ribbon-like pattern.

Occasionally, when a large amount of tumour tissue is present, the 'carcinoid syndrome' may be present. This consists of attacks of flushing of the skin, cyanosis, and hypertension, perhaps associated with lesions of the endocardium especially affecting valves of the right side of the heart. The $\overrightarrow{\vec{s}}$ syndrome is thought to be due to the secretion of $\overline{0}$ 5-hydroxytryptamine (serotonin) by the tumour cells (Gabrilove et al., 1969). The excess 5- के hydroxytryptamine excreted by the tumour cells $\stackrel{\nabla}{\varnothing}$ is oxidized in the liver and lungs by the enzyme amine oxidase; with the formation of 5-hydroxyindoleacetic acid (5-HIAA) which is excreted in the urine. The estimation of urinary 5-HIAA is used as a diagnostic test for the detection of carcinoid tumours.

None of the 16 patients previously reported with carcinoid of the thymus had the carcinoid syndrome, nor did our patient. No sweats, flushes, rashes, palpitation, diarrhoea, bronchospasm, nor paresthesias were reported in these patients. An 을 explanation for this could be that most of the endocrine products are metabolized in the lungs $\rightarrow$ before they reach the systemic circulation due to an abnormal blood supply to these tumours. Nor- $\stackrel{2}{\oplus}$ mally, the thymic veins drain into the brachio- $\vec{T}$ cephalic and thyroid veins.

With thymic carcinoid, the tumour may displace all thymic tissue. The pattern of growth (Fig. 4) is in completely divided lobules of fibrous trabeculae. Large round to oval 'balls' and areas of central necrosis with calcification can be present. Normal thymus may be near the capsule, but it may also be seen in the mass.

The differential diagnoses of mediastinal tumours must include ectopic parathyroid tumour, chemodectoma, bronchial adenoma, thymoma, neurogenic tumour, neurofibroma, teratodermoid tumour (teratoma), cyst (pericardial or broncho- 을 genic), lymphoma (Hodgkin's), intrathoracic $\underset{x}{x}$ goitre, mesenchymal tumour (fibrosarcoma), $\frac{\dot{\sigma}}{3}$ vascular tumour (capillary haemangioma), seminoma (Oldham, 1971), aortic aneurysm, pseudo- o coarctation, hiatal hernia, and metastatic cancer.

The clinical symptoms of a mediastinal tumour 욱 are chest pain, dyspnoea, cough, shortness of $D$ breath, dysphagia, pneumonia, hoarseness, and upper respiratory tract infections (Heimburger, $N$ Battersby, and Vellios, 1963; Oldham, 1971). All of these are not specific for the presence of a $N$ mediastinal tumour. The pain may be excruciating and radiate to the back and arms, as it did in our patient.

The evaluation of the patient should include $\frac{}{\mathbb{D}}$ chest films, tomograms of the tumour, fluoro- $\stackrel{\oplus}{+}$ scopy, barium meal, radioisotope scanning, 0 bronchoscopy, angiography, and mediastinoscopy. However, we would agree with Heimburger et al. $\stackrel{\AA}{\Omega}$ (1963) that special diagnostic procedures are help- $\stackrel{\mathbb{D}}{\mathbb{D}}$ ful in detecting aneurysms, diaphragmatic hernia, 
and primary tumours of the lung, but no study can give specific diagnosis in the majority of primary mediastinal tumours. Thoracotomy, with either biopsy or surgical removal, has proved the only reliable method of diagnosis.

Complete surgical excision of carcinoid tumours, if possible, has been recommended consistently (Lattes, 1962; Heimburger et al., 1963; Wilkins, Edmunds, and Castleman, 1966; Postlethwait, 1966; Cohn and Grimes, 1970). Cohn and Grimes (1970) add that patients 'can expect not only reasonable relief but also complete obliteration of symptoms'. With the current status of thoracic surgery and postoperative care, the operative mortality for excision of tumours of the mediastinum is low. Oldham (1971) reported a hospital mortality rate of $1.8 \%$ for 164 patients. For our patient the median sternotomy offered good exposure for resection of the anterior mediastinal neoplasm.

Postoperative irradiation was not used for two reasons: the malignant potential of carcinoid of the thymus is unknown and there is the possibility of increased morbidity from mediastinal irradiation.

\section{REFERENCES}

Bensch, K. G., Corrin, B., Pariente, R., and Spencer, H. (1968): Oat-cell carcinoma of the lung. Its origin and relationship to bronchial carcinoid. Cancer, 22, 1163.

Cohn, L. H. and Grimes, O. F. (1970). Surgical management of thymic neoplasms. Surgery, Gynecology and Obstetrics, 131, 206.

Gabrilove, J. L., Nicolis, G. L., and Kirschner, P. A. (1969). Cushing's syndrome in association with carcinoid tumor. Annals of Surgery, 169, 240.

Heimburger, I., Battersby, J. S., and Vellios, F. (1963). Primary neoplasms of the mediastinum. Archives of Surgery, 86, 978.

Kultschitzky, N. K. (1897). Zur Frage über den Bau des Darmkanals. Archiv für Mikrobiologie Anatomie, 49, 7.
Lattes, R. (1962). Thymoma and other tumors of the thymus. An analysis of 107 cases. Cancer, 15, 1224.

Macadam, R. F. and Vetters, J. M. (1969). Fine structural evidence for hormone secretion by a human thymic tumour. Journal of Clinical Pathology, 22, 407.

MacDonald, R. A. (1956). A study of 356 carcinoids of the gastrointestinal tract; report of four new cases of the carcinoid syndrome. American Journal of Medicine, 21, 867.

Oberndorfer, S. (1907). Karzinoide Tumoren des Dunndarms. Frankfurt Zeitschrift für Pathologie, $1,426$.

Oldham, H. N. Jr. (1971). Mediastinal tumors and cysts. Annals of Thoracic Surgery, 11, 246.

Pearson, C. M. and Fitzgerald, P. J. (1949). Carcinoid tumors. A re-emphasis of their malignant nature. Cancer, 1005.

Peart, W. S., Porter, K. A., Robertson, J. I. S., Sandler, M., and Baldock, E. (1963). Carcinoid syndrom due to pancreatic-duct neoplasm secreting 5-hydroxytryptophan and 5-hydroxytryptamine. Lancet, 1, 239.

Postlethwait, R. W. (1966). Gastrointestinal carcinoid tumors. A review. Postgraduate Medicine, 40, 445 .

Rosai, J. and Higa, E. (1972). Mediastinal endocrine neoplasm, of probable thymic origin, related to carcinoid tumor. Clinicopathologic study of 8 cases. Cancer, 29, 1061.

Shiffman, M. A. and Juler, G. (1964). Carcinoid of the biliary tract. Archives of Surgery, 89, 1113.

Steel, K., Baerg, R. D., and Adams, D. O. (1967). Cushing's syndrome in association with a carcinoid tumor of the lung. Journal of Clinical Endocrinology and Metabolism, 27, 1285.

Wilkins, E. W. Jr., Edmunds, L. H. Jr., and Castleman, B. (1966). Cases of thymoma at the Massachusetts General Hospital. Journal of Thoracic and Cardiovascular Surgery, 52, 322.

Requests for reprints to: Dr. J. L. Ochsner, Alton Ochsner Medical Foundation, 1514 Jefferson Highway, New Orleans, Louisiana, 70121, USA. 